\title{
Diabetic Vascular Disorder
}

National Cancer Institute

\section{Source}

National Cancer Institute. Diabetic Vascular Disorder. NCI Thesaurus. Code C35610.

Vascular disorders resulting from diabetes mellitus. 